\title{
PTU-133 CANALYSIS OF TRAINER FEEDBACK FROM THE JETS E-PORTFOLIO
}

doi:10.1136/gut.2011.239301.261

S Samji, ${ }^{*}$ K Dowler, R Valori, P Dunckley Gastroenterology, GHNHSFT, Gloucester, UK

Introduction The JAG Endoscopy Training System (JETS) e-portfolio was released in September 2009 and has been set up by over $75 \%$ of trusts at the time of writing. Following each training list, trainees have the option to submit anonymised feedback on the training received. This feedback populates the trainer's e-portfolio and informs the training programme director (TPD) on the quality of training received at a trust level (anonymised data). Characteristics of a good trainer include: interpersonal skills, endoscopic skills, technical teaching attributes and motivation to teach. ${ }^{1}$

Recent surveys have shown that many trainees feel inadequately supervised in endoscopy throughout their training. ${ }^{23}$ Quality of time spent with a trainer therefore becomes more invaluable. The standard of training can now be determined by the trainees themselves.

Methods Since the release of the JETS e-portfolio, 3074 trainer feedback forms have been completed. At the time of writing an average of 320 feedback forms are being completed each month by 140 trainees. In total, 376 trainees have completed trainer feedback on the JETS e-portfolio (out of 712 trainees currently using the system).

Using a Likert scale trainees can provide scores on items such as: giving constructive feedback (FB), providing fair evaluation, putting the trainee at ease and whether the endoscopist is a skilled teacher. FB scores were evaluated by either averaging scores over a calendar year comparing scores over time or by comparing the first and last 5 scores of the trainers from September 2009.

Results See table 1. $87 \%$ of trainers obtained scores of over 4.0. Average FB scores were relatively stable (4.45 in 2008 to 4.48 in '09 and 4.50 in'10). The median score was 4.52 .

Table 1 PTU-133 Average feedback score of trainers in 1 year and percentage of trainers receiving this score

\begin{tabular}{llc}
\hline Average FB Score in $\mathbf{1}$ year & Number of Trainers & Percentage of scores \\
\hline $5-4.9$ & 39 & 8 \\
4.8 & 35 & 7 \\
4.7 & 63 & 13 \\
4.6 & 68 & 14 \\
4.5 & 64 & 13 \\
4.4 & 55 & 11 \\
4.3 & 55 & 11 \\
$4.2-4$ & 81 & 17 \\
$<3.9$ & 20 & 4 \\
\hline
\end{tabular}

Conclusion This data confirms that trainees are willing to provide anonymous feedback on training received. The feedback then populates the trainer's portfolio enabling the trainers to reflect on their training ability. Furthermore, TPDs can now access summated, anonymised feedback data for a trust, therefore supporting quality assurance of training for trainees in that region.

On the whole the majority of UK trainees that gave FB anonymously on the JETS website feel they receive a high standard 
of training. This correlates with a previous study when $75 \%$ of trainees rated their endoscopy training as quite good to excellent. $^{2}$

Competing interests None.

Keywords e-portfolio, feedback, trainer.

\section{REFERENCES}

1. Wells, C. 2009.The characteristics of an excellent endoscopy trainer. Frontline Gastroenterology. 1:13-18.

2. Wells, C., Inglis, S. and Barton, R. 2009. Trainees in gastroenterology views on teaching in clinical gastroenterology and endoscopy. Medical Teacher. 31:138-144.

3. Bisschops, R., Wilmer, A, and Tack, J. 2002. A survey on gastroenterology training in Europe. Gut. 50:724-729. 